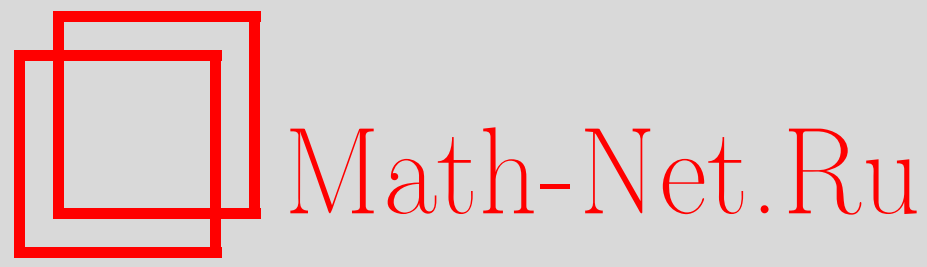

S. Louhichi, Moment inequalities for sums of certain dependent random variables, Теория вероятн. и ее примен., 2002, том 47, выпуск 4, 747-763

DOI: https://doi.org/10.4213/tvp3778

Использование Общероссийского математического портала MathNet.Ru подразумевает, что вы прочитали и согласны с пользовательским соглашением

http://www . mathnet.ru/rus/agreement

Параметры загрузки:

IP : 54.157 .27 .8

26 апреля 2023 г., 13:26:56

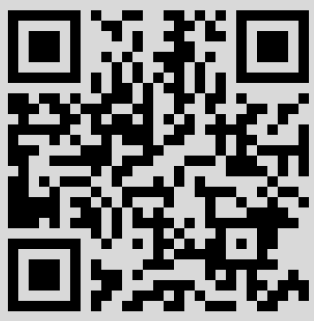




\section{MOMENT INEQUALITIES FOR SUMS OF CERTAIN DEPENDENT RANDOM VARIABLES}

Представлен ряд примеров зависимых последовательностей со свойством «некоррелированность влечет независимость». Изучаются моментные неравенства для этих последовательностей.

Ключевые слова и фразы: моментные неравенства, неравенства типа Розенталя, отрицательная зависимость, ассоциированность.

1. Introduction, statement of results and discussion. Let $X=$ $\left(X_{1}, \ldots, X_{n}\right)$ be a centered vector of real-valued random variables (r.v.'s) with finite variance. Put $S_{n}=X_{1}+\cdots+X_{n}$, with the convention that $S_{0}=0$ and let $r>2$ be a fixed real number. The Rosenthal inequality known for independent and identically distributed random variables as

$$
\mathbf{E}\left|S_{n}\right|^{r} \leqslant C_{r}\left\{\left(\mathbf{D} S_{n}\right)^{r / 2}+n \mathbf{E}\left|X_{1}\right|^{r}\right\}
$$

has got a lot of applications in probability and statistics. Its main advantage is that the controls of the higher order moments of the partial sums are reduced to those of order 2. We refer for instance to Rosenthal [21], Petrov [18] for proofs and other versions of moment inequalities and to Stout [26], Bretagnolle and Huber [4], Peskir and Shiryaev [17] for various applications of inequality (1).

Since almost all the models from the statistical theory are not independent and in view of the utility of Rosenthal's inequality in such a field, several authors are interested in the extension of inequality (1) to the depending setting. Those extensions are far from being trivial and depend widely on the dependence structure of the processes.

A very well known measure of dependence in the probabilistic literature is described by the mixing coefficients. Versions of Rosenthal's inequality for mixing sequences were established by several authors. We refer to the works of Doukhan [9], Doukhan and Portal [8], Ibragimov and Linnik [13], Rio ([19], [20]), Shao ([22], [25]),... .

*Université de Paris-Sud, Probabilités, statistique et modélisation, Bât. 425, 91405 Orsay Cedex, France; e-mail: sana.louhichi@math.u-psud.fr 
Pursuing the objective of Doukhan and Louhichi [10], we would like to prove in this paper a unifying inequality of type (1) for some sequences $\left(X_{i}\right)_{i \in \mathbf{N}}$ obeying the property «the noncorrelation yields the independence», which is described by the following covariance inequality:

$$
\left|\operatorname{cov}\left(h\left(X_{i}, i \in A\right), k\left(X_{j}, j \in B\right)\right)\right| \leqslant \sum_{i \in A} \sum_{j \in B}\left\|\frac{\partial h}{\partial x_{i}}\right\|_{\infty}\left\|\frac{\partial k}{\partial x_{j}}\right\|_{\infty}\left|\operatorname{cov}\left(X_{i}, X_{j}\right)\right|
$$

where $A$ and $B$ are arbitrary finite disjoint subsets of $\mathbf{N}$ and $h, k$ are any real-valued functions having uniformly bounded first derivatives.

Inequality (2) appears as a particular case of the general notion of weak dependence stated in [1] or independently in [10].

We have called in [15], (AG) sequences the processes fulfilling the covariance inequality (2). This terminology is due to the fact that both associated and Gaussian processes fulfill inequality (2). Associated random variables were introduced by Esary, Proschan, and Walkup [11] and independently by Fortuin, Kasteleyn, and Ginibre [12]. Sequences $\left(X_{i}\right)_{i \in \mathbf{N}}$ are associated or fulfilling the FKG inequality (in the statistical mechanics terminology) if for all coordinatewise nondecreasing functions $f, g$ and all $n \in \mathbf{N}$ there holds:

$$
\operatorname{cov}\left(f\left(X_{1}, \ldots, X_{n}\right), g\left(X_{1}, \ldots, X_{n}\right)\right) \geqslant 0 .
$$

The (AG) property for associated processes follows from Lemma 3.1 in [3]. Birkel [2] was the first to establish moment inequalities under association. He proved the moment bound $\mathbf{E}\left|S_{n}\right|^{r}=O\left(n^{r / 2}\right)$ (i.e., Marcinkiewicz-Zygmund bound) under optimal conditions. Bulinski [6] proved the analog of this bound for random fields under optimal conditions as well, see also [5].

Rosenthal-type inequality for associated processes is recently established by Shao and Yu [23] for functions of associated sequences and by Vronski [27] for associated random fields.

The (AG) property is also satisfied by negatively associated processes. The sequence $\left(X_{i}\right)_{i \in \mathbf{N}}$ is said to be negatively associated if for every pair of disjoint subsets $A$ and $B$ of $\mathbf{N}$

$$
\operatorname{cov}\left(f\left(X_{i}, i \in A\right), g\left(X_{j}, j \in B\right)\right) \leqslant 0,
$$

whenever $f$ and $g$ are coordinatewise nondecreasing functions. This definition was introduced by Joag Dev [14]. The (AG) property for negatively associated processes follows from Lemma 1 in [7]:

In the negatively dependent setting, moment bounds were established by Matula [16], cf. also [24] and the references therein.

For $(A G)$ sequences, we propose the following moment inequality which will be the main result of this paper.

Theorem 1. Let $r$ be a fixed real number, $r>2$. Let $\left(X_{n}\right)$ be a strictly stationary sequence of centered and (AG) r.v.'s. Suppose moreover that this 
sequence is bounded by $M$. Then there exists a positive constant $C_{r}$ depending only on $r$, such that

$$
\mathbf{E}\left|S_{n}\right|^{r} \leqslant C_{r}\left[s_{n}^{r}+\sum_{k=1}^{n} \sum_{i=0}^{k-1} M^{r-2}(i+1)^{r-2} \mid \operatorname{cov}\left(X_{1}, X_{1+i}\right)\right],
$$

where $s_{n}^{2}:=n \sum_{i=0}^{n}\left|\operatorname{cov}\left(X_{1}, X_{1+i}\right)\right|$.

Theorem 1 gives then a unifying Rosenthal-type inequality for at least two models: associated or negatively associated processes.

An immediate consequence of Theorem 1 is the following corollary.

Corollary 1. Let $r$ be a fixed real number, $r>2$. Let $\left(X_{n}\right)$ be a strictly stationary sequence of centered, (AG) r.v.'s bounded by M. Suppose that

$$
v_{r}:=M^{-2} \sum_{i=0}^{+\infty}(i+1)^{r-2}\left|\operatorname{cov}\left(X_{1}, X_{1+i}\right)\right|<+\infty,
$$

then there exists a positive constant depending only on $r$ and on $v_{r}$ such that

$$
\mathbf{E}\left|S_{n}\right|^{r} \leqslant C_{r}\left[n^{r / 2} M^{r}+n M^{r}\right] .
$$

Inequality (3) is close to (1). The linear term (the second term in the right-hand side (RHS) of (3)) is of order $n$ under the summability condition $\sum_{i=0}^{+\infty}(i+1)^{r-2}\left|\operatorname{cov}\left(X_{1}, X_{1+i}\right)\right|<+\infty$, in contrast with the corresponding term in the Shao and Yu inequality (see [23]) which is of order $n^{1+\varepsilon}$ (for some $\varepsilon>0$ ). Their inequality is however available for nonbounded functions of associated random variables. In this latter context, Vronski [27] proves versions of Rosenthal inequality for random fields. For bounded associated sequences Vronski's inequalities apply, and they lead to inequality (5) under the summability condition $\sum_{i=0}^{+\infty}(i+1)^{r-2} U(r)<+\infty$, where $U(r)$ is the Cox-Grimmett coefficient defined by

$$
U(r)=\sup _{i \in \mathbf{N}} \sum_{j:|i-j| \geqslant r} \operatorname{cov}\left(X_{i}, X_{j}\right) .
$$

An immediate consequence of Theorem 1 is the following MarcinkiewiczZygmund bound.

Corollary 2. Let $r$ be a fixed real number, $r>2$. Let $\left(X_{n}\right)$ be a strictly stationary sequence of centered, (AG) r.v.'s bounded by $M$. Suppose that

$$
\left|\operatorname{cov}\left(X_{1}, X_{1+i}\right)\right|=O\left(i^{-r / 2}\right), \quad \text { as } i \rightarrow+\infty .
$$

Then

$$
\mathbf{E}\left|S_{n}\right|^{r}=O\left(n^{r / 2}\right) .
$$

For bounded associated sequences, condition (6) is shown to be optimal for the Marcinkiewicz-Zygmund bound (7) (cf. [2]).

In the next section we prove Theorem 1 . The method for its proof is a generalization of the Lindeberg decomposition to an order $r>2$. This method was first developed by Rio [20] for mixing sequences and for $r \in] 2,3]$.

Some auxiliary lemmas, needed for the proofs, are proved in the Appendix. 
2. Proofs. In the sequel $p$ is a fixed integer not less than 2 and $\Phi_{p}$ is the class of functions defined by:

$$
\begin{gathered}
\Phi_{p}:=\left\{\phi: \mathbf{R}^{+} \rightarrow \mathbf{R}^{+} ; \phi(0)=\phi^{\prime}(0)=\cdots=\phi^{(p-1)}(0)=0,\right. \\
\left.\phi^{(p)} \text { is nondecreasing, concave }\right\} .
\end{gathered}
$$

Let $\phi$ be a function of the set $\Phi_{p}$. Theorem 1 is proved if we suitably control $\mathbf{E} \phi\left(\left|S_{n}\right|\right.$ ) (since the function $x \rightarrow x^{r}$, for $\left.r \in\right] p, p+1$ ] is one of those functions $\phi$ ).

Such a control will be done into four steps.

2.1. Step 1. The purpose of Step 1 is to reduce the control of $\mathbf{E} \phi\left(\left|S_{n}\right|\right)$ to that of a suitable polynomial function of $\left|S_{n}\right|$, as follows.

Define the function $g_{p}: \mathbf{R}^{+} \times \mathbf{R} \rightarrow \mathbf{R}^{+}$by

$$
g_{p}(t, x):=\frac{1}{(p+1) !}\left[x^{p+1} \mathbf{1}_{0 \leqslant x \leqslant t}+\left(x^{p+1}-(x-t)^{p+1}\right) \mathbf{1}_{t<x}\right]
$$

for any $x \geqslant 0$ and $g_{p}(t, x)=g_{p}(t,-x)$.

The following lemma is a generalization of equality (4.3) in [20], which was written for $p=2$.

Lemma 1. Let $p$ be a fixed integer, $p \geqslant 2$. Let $\phi \in \Phi_{p}$. Suppose that $\phi^{(p+1)}$ exists and that $\lim _{x \rightarrow \infty} \phi^{(p+1)}(x)=0$. Then

$$
\phi(x)=\int_{0}^{+\infty} g_{p}(t, x) \nu_{p}(d t)
$$

where $\nu_{p}$ is the Stieltjes measure of $-\phi_{p}^{(p+1)}$ defined by $\nu_{p}(d t)=-d \phi^{(p+1)}(t)$.

Lemma 1 reduces then the estimation of $\mathbf{E} \phi\left(\left|S_{n}\right|\right)$ to that of $\mathbf{E} g_{p}\left(t, S_{n}\right)$.

2.2. Step 2: Main terms. The purpose of Step 2 is then to give bounds of $\mathbf{E} f\left(S_{n}\right)$, for real-valued functions $f$ belonging to a suitable set containing the functions $x \rightarrow g_{p}(t, x)$. For this, let $\mathscr{C}_{p}$ be the class of realvalued, $p$ times continuously differentiable functions $f$ such that $f(0)=\cdots=$ $f^{(p)}(0)=0$.

Let $\mathscr{F}_{p}\left(b_{1}, b_{2}\right)$ be the subclass of $\mathscr{C}_{p+1}$ such that $\left\|f^{(p)}\right\|_{\infty} \leqslant b_{1}$ and $\left\|f^{(p+1)}\right\|_{\infty} \leqslant b_{2}$, where $\left\|f^{(i)}\right\|_{\infty}=\sup _{x \in \mathbf{R}}\left|f^{(i)}(x)\right|$ and $f^{(i)}$ denotes the differential of order $i$ of the function $f$.

In this step, we give an estimation of $\mathbf{E} f\left(S_{n}\right)$, for $f \in \mathscr{F}_{p}\left(b_{1}, b_{2}\right)$. Let us note that the function $g_{p}$ as defined by $(8)$ belongs to the set $\mathscr{F}_{p}(t, 1)$.

We first exhibit the mains terms of our calculations.

$\mathrm{N}$ o t a $\mathrm{t}$ i o $\mathrm{n}$. We denote by $\sum_{(p-2)}$ the sum over $i_{1}, \ldots, i_{p-2}$ such that $0:=i_{0} \leqslant i_{1} \leqslant \cdots \leqslant i_{p-2} \leqslant k-1$, that is, $\sum_{0 \leqslant i_{1} \leqslant \cdots \leqslant i_{p-2} \leqslant k-1}$. We define

$$
\mathbf{E}_{p-2, k}(\Delta f)=\sup _{0 \leqslant u \leqslant 1} \sum_{(p-2)}\left|\mathbf{E} X_{k} X_{k-i_{1}} \cdots X_{k-i_{p-2}} \Delta_{p-2, k}(f, u)\right| \text {, }
$$


where

$$
\begin{aligned}
\Delta_{p-2, k}(f): & =\Delta_{p-2, k}(f, u)=\left[f\left(S_{k-i_{p-2}-1}+u X_{k-i_{p-2}}\right)-f\left(S_{k-i_{p-2}-1}\right)\right] \\
& =u X_{k-i_{p-2}} \int_{0}^{1} f^{\prime}\left(S_{k-i_{p-2}-1}+u v X_{k-i_{p-2}}\right) d v
\end{aligned}
$$

Finally, we set for $p \geqslant 2$,

$$
\mathbf{E}_{p-2, k}(f)=\sum_{(p-2)}\left|\mathbf{E} X_{k} X_{k-i_{1}} \cdots X_{k-i_{p-2}} f\left(S_{k-i_{p-2}-1}\right)\right| .
$$

Let us note that $i_{0}=0$,

$$
\mathbf{E}_{0, k}(f)=\left|\mathbf{E} X_{k} f\left(S_{k-1}\right)\right| \quad \text { and that } \quad \mathbf{E}_{0, k}(\Delta f)=\sup _{0 \leqslant u \leqslant 1}\left|\mathbf{E} X_{k} \Delta_{0, k}(f, u)\right| .
$$

For any real-valued function $f$ of the set $\mathscr{F}_{p}\left(b_{1}, b_{2}\right)$, the quantity $\left|\mathbf{E}\left(f\left(S_{n}\right)\right)\right|$ is evaluated by means of the main terms $\mathbf{E}_{p-2, k}\left(f^{(p-1)}\right)$ and $\mathbf{E}_{p-2, k}\left(\Delta f^{(p-1)}\right)$ as shows the following lemma.

Lemma 2. Let $p$ be a fixed integer, $p \geqslant 2$. Let $\left(X_{n}\right)$ be a sequence of (AG) r.v.'s, centered and bounded by $M$. There exists a positive constant $C_{p}$ depending only on $p$, such that for any $f \in \mathscr{F}_{p}\left(b_{1}, b_{2}\right)$

$$
\begin{aligned}
\left|\mathbf{E}\left(f\left(S_{n}\right)\right)\right| \leqslant C_{p}\{ & s_{n}^{p}\left(b_{1} \wedge b_{2} s_{n}\right)+\left(b_{1} \wedge b_{2} M\right) M^{p-2} \sum_{k=1}^{n} \sum_{i=0}^{k-1}\left|\operatorname{cov}\left(X_{k}, X_{k-i}\right)\right| \\
& \left.+\sum_{k=1}^{n} \mathbf{E}_{p-2, k}\left(f^{(p-1)}\right)+\sum_{k=1}^{n} \mathbf{E}_{p-2, k}\left(\Delta f^{(p-1)}\right)\right\} .
\end{aligned}
$$

From now $C_{p}$ denotes a positive constant depending only on $p$ and that will be different from line to line.

2.3. Step 3: Evaluation of the main terms $\mathbf{E}_{p-2, k}(f)$ and $\mathbf{E}_{p-2, k}(\Delta f)$. The object of this step is to evaluate the main terms $\mathbf{E}_{p-2, k}(f)$ and $\mathbf{E}_{p-2, k}(\Delta f)$ of Lemma 2 . This evaluation evokes the following covariance quantities:

$$
M_{m, n}=M^{m-2} \sum_{k=1}^{n} \sum_{i=0}^{k-1}(i+1)^{m-2}\left|\operatorname{cov}\left(X_{1}, X_{i+1}\right)\right|, \quad \text { for } \quad 2 \leqslant m \leqslant p,
$$

and

$$
\begin{aligned}
& M_{m, n}\left(b_{1}, b_{2}\right) \\
& :=\sum_{k=1}^{n} \sum_{r=0}^{k-1}\left(b_{1} \wedge b_{2}(r+1) M\right)(r+1)^{m-2} M^{m-2}\left|\operatorname{cov}\left(X_{1}, X_{r+1}\right)\right| .
\end{aligned}
$$

Let us note that $M_{2, n}$ is close to $\mathbf{D} S_{n}$ and that in the i.i.d. case $M_{2, n}=n \mathbf{D} X_{1}$.

We now state the basic technical lemma of this paper. 
Lemma 3. Let $f$ be a real-valued function of the set $\mathscr{F}_{1}\left(b_{1}, b_{2}\right)$. Let $\left(X_{n}\right)$ be a centered sequence of (AG) r.v.'s. Suppose that $\left(X_{n}\right)$ is uniformly bounded by $M$. Then, for any integer $p \geqslant 2$, there exists a positive constant $C_{p}$ depending only on $p$, for which

$$
\begin{aligned}
& \sum_{k=1}^{n} \mathbf{E}_{p-2, k}(\Delta f)+\sum_{k=1}^{n} \mathbf{E}_{p-2, k}(f) \\
& \quad \leqslant C_{p}\left\{s_{n}^{p}\left(b_{1} \wedge b_{2} s_{n}\right)+\sum_{m=2}^{p-2} M_{m, n} M_{p-m, n}\left(b_{1}, b_{2}\right)+M_{p, n}\left(b_{1}, b_{2}\right)\right\},
\end{aligned}
$$

where the sum $\sum_{m=2}^{p-2}$ equals to 0 , whenever $p \in\{2,3\}$.

2.4. Step 4: End of the proof of Theorem 1. Finally, we combine the three previous steps in order to finish the proof of Theorem 1. Let us explain. We first make use of Lemma 1, together with Fubini's theorem, to obtain:

$$
\mathbf{E} \phi\left(\left|S_{n}\right|\right)=\int_{0}^{+\infty} \mathbf{E} g_{p}\left(t, S_{n}\right) \nu_{p}(d t) .
$$

Now, we recall that the functions $x \rightarrow g_{p}(t, x)$ and $x \rightarrow g_{p}^{(p-1)}(t, x)$ belong respectively to $\mathscr{F}_{p}(t, 1)$ and to $\mathscr{F}_{1}(t, 1)$ (in fact if $f \in \mathscr{F}_{p}(t, 1)$, then $\left.f^{(p-1)} \in \mathscr{F}_{1}(t, 1)\right)$. Hence we deduce by applying Lemma 2 to the function $x \rightarrow g_{p}(t, x)$ and Lemma 3 to $x \rightarrow g_{p}^{(p-1)}(t, x)$ :

$$
\mathbf{E} g_{p}\left(t, S_{n}\right) \leqslant C_{p}\left\{\sum_{m=2}^{p-2} M_{m, n} M_{p-m, n}(t, 1)+M_{p, n}(t, 1)+s_{n}^{p}\left(t \wedge s_{n}\right)\right\} .
$$

Taking into account Lemma 1 and the fact $g^{(p)}(x)=x \wedge t$, we deduce that

$$
\phi^{(p)}(x)=\int_{0}^{+\infty}(t \wedge x) \nu_{p}(d t) .
$$

Inequalities (12), (13) and (14) yield:

$$
\begin{aligned}
\mathbf{E} \phi\left(\left|S_{n}\right|\right) \leqslant C_{p}\{ & \sum_{k=1}^{n} \sum_{i=0}^{k-1} \phi^{(p)}(M(i+1)) M^{p-2}(i+1)^{p-2} \\
& \times\left|\operatorname{cov}\left(X_{1}, X_{1+i}\right)\right|+s_{n}^{p} \phi^{(p)}\left(s_{n}\right) \\
& +\sum_{m=2}^{p-2} M_{m, n}\left(\sum_{k=1}^{n} \sum_{i=0}^{k-1} \phi^{(p)}(M(i+1)) M^{p-m-2}(i+1)^{p-m-2}\right. \\
& \left.\left.\times\left|\operatorname{cov}\left(X_{1}, X_{1+i}\right)\right|\right)\right\} .
\end{aligned}
$$

Now, we use the concavity property of the function $\phi^{(p)}$ :

$$
\phi(x)=\frac{x^{p}}{(p-1) !} \int_{0}^{1}(1-t)^{p-1} \phi^{(p)}(t x) d t \geqslant x^{p} \phi^{(p)}(x) \int_{0}^{1} \frac{t(1-t)^{p-1}}{(p-1) !} d t
$$

to deduce that

$$
x^{p} \phi^{(p)}(x) \leqslant C_{p} \phi(x) .
$$


We conclude, combining inequalities (15) and (16):

$$
\begin{gathered}
\mathbf{E} \phi\left(\left|S_{n}\right|\right) \leqslant C_{p}\left\{\sum_{k=1}^{n} \sum_{i=0}^{k-1} \phi(M(i+1)) M^{-2}(i+1)^{-2}\left|\operatorname{cov}\left(X_{1}, X_{1+i}\right)\right|+\phi\left(s_{n}\right)\right. \\
+\sum_{m=2}^{p-2} M_{m, n}\left(\sum_{k=1}^{n} \sum_{i=0}^{k-1} \phi(M(i+1)) M^{-m-2}(i+1)^{-m-2}\right. \\
\left.\left.\times\left|\operatorname{cov}\left(X_{1}, X_{1+i}\right)\right|\right)\right\} .
\end{gathered}
$$

The last inequality applied to $\phi(x)=x^{r}$, for $\left.\left.r \in\right] p, p+1\right]$, leads to

$$
\begin{aligned}
\mathbf{E}\left|S_{n}\right|^{r} \leqslant C_{r} & \left\{\sum_{k=1}^{n} \sum_{i=0}^{k-1} M^{r-2}(i+1)^{r-2}\left|\operatorname{cov}\left(X_{1}, X_{1+i}\right)\right|+s_{n}^{r}\right. \\
& \left.+\sum_{m=2}^{p-2} M_{m, n} M_{r-m, n}\right\} .
\end{aligned}
$$

In order to control the term $M_{m, n} M_{r-m, n}$ of the last inequality, we need the following lemma (that we prove in the Appendix).

Lemma 4 (Analog of Hölder's inequalities). We have, for any $r>4$, $2<m<r$,

$$
M_{m, n} M_{r-m, n} \leqslant s_{n}^{2 r /(r-2)} M_{r, n}^{(r-4) /(r-2)} \leqslant s_{n}^{r}+M_{r, n} .
$$

We also have, for any $b_{1}, b_{2}>0, r>2$, and $2 \leqslant m<r$,

$$
\begin{aligned}
s_{n}^{r-m}\left(b_{1} \wedge b_{2} s_{n}\right) M_{m, n} & \leqslant s_{n}^{r}\left(b_{1} \wedge b_{2} s_{n}\right)+M_{r, n}\left(b_{1}, b_{2}\right), \\
s_{n}^{r-m} M_{m, n}\left(b_{1}, b_{2}\right) & \leqslant s_{n}^{r}\left(b_{1} \wedge b_{2} s_{n}\right)+M_{r, n}\left(b_{1}, b_{2}\right) .
\end{aligned}
$$

The proof of Theorem 1 is now complete, using inequality (17), together with (18) and (20) (recall that $M_{2, n} \leqslant s_{n}^{2}$ ).

3. Appendix. In this section, we prove all the auxiliary lemmas needed for the proof of Theorem 1 .

$\mathrm{P}$ r o of of $\mathrm{L}$ e $\mathrm{mm}$ a 2 . By induction on $p \geqslant 2$, and using the following decomposition: for $g \in \mathscr{C}_{1}$,

$$
g\left(S_{n}\right)=\sum_{k=1}^{n}\left[g\left(S_{k}\right)-g\left(S_{k-1}\right)\right]=\sum_{k=1}^{n} X_{k} \int_{0}^{1} g^{\prime}\left(S_{k-1}+u X_{k}\right) d u
$$

we show that, for any $f \in \mathscr{C}_{p-1}$,

$$
\left|\mathbf{E}\left(f\left(S_{n}\right)\right)\right| \leqslant C_{p} \sum_{k=1}^{n}\left[\mathbf{E}_{p-2, k}\left(f^{(p-1)}\right)+\mathbf{E}_{p-2, k}\left(\Delta f^{(p-1)}\right)\right]+\sum_{k=1}^{n} \mathbf{R}_{p, k}(f),
$$

where

$$
\mathbf{R}_{p, k}(f):=\left|\mathbf{E}\left[f\left(S_{k}\right)-f\left(S_{k-1}\right)-\cdots-\frac{X_{k}^{p-1}}{(p-1) !} f^{(p-1)}\left(S_{k-1}\right)\right]\right| .
$$


Let now $f$ be a fixed function of the set $\mathscr{F}_{p}\left(b_{1}, b_{2}\right)$. In view of (22), Lemma 2 is proved if we suitably evaluate $\mathbf{R}_{p, k}(f)$. Clearly

$$
\begin{aligned}
\mathbf{R}_{p, k}(f) & \leqslant \mathbf{R}_{p+1, k}(f)+\left|\operatorname{cov}\left(X_{k}^{p}, f^{(p)}\left(S_{k-1}\right)\right)\right|+\mathbf{E}\left|X_{k}^{p}\right| \mathbf{E}\left|f^{(p)}\right|\left(S_{k-1}\right) \\
& =: I_{1, k}+I_{2, k}+I_{3, k} .
\end{aligned}
$$

Taylor's formula and the (AG) property yield:

$$
\begin{aligned}
I_{1, k} & \leqslant \mathbf{E}\left(\left|X_{k}\right|^{p}\left(b_{1} \wedge b_{2}\left|X_{k}\right|\right)\right) \\
I_{2, k} & \leqslant c_{p}\left[b_{p} M^{p-2} \mathbf{E}\left|X_{k}\right|^{2} \wedge M^{p-1} b_{p+1} \sum_{i=0}^{k-1}\left|\operatorname{cov}\left(X_{k}, X_{k-i}\right)\right|\right] \\
& \leqslant c_{p}\left(b_{p} \wedge b_{p+1} M\right) M^{p-2} \sum_{i=0}^{k-1}\left|\operatorname{cov}\left(X_{k}, X_{k-i}\right)\right|, \quad \text { finally } \\
I_{3, k} & \leqslant \mathbf{E}\left|X_{k}^{p}\right|\left(b_{1} \wedge b_{2} s_{n}\right) \\
& \leqslant \mathbf{E}\left|X_{k}^{p}\right|\left(b_{1} \wedge b_{2} s_{n}\right) \mathbf{1}_{\left|X_{k}\right| \leqslant s_{n}}+\mathbf{E}\left|X_{k}^{p}\right|\left(b_{1} \wedge b_{2} s_{n}\right) \mathbf{1}_{\left|X_{k}\right|>s_{n}} \\
& \leqslant s_{n}^{p-2}\left(b_{1} \wedge b_{2} s_{n}\right) \mathbf{E}\left(X_{k}^{2}\right)+\mathbf{E}\left(\left|X_{k}\right|^{p}\left(b_{1} \wedge b_{2}\left|X_{k}\right|\right)\right) .
\end{aligned}
$$

The proof of Lemma 2 is complete by noting that $\sum_{k=1}^{n} \mathbf{E}\left(X_{k}^{2}\right) \leqslant s_{n}^{2}$, and

$$
\sum_{k=1}^{n} \mathbf{E}\left(\left|X_{k}\right|^{p}\left(b_{1} \wedge b_{2}\left|X_{k}\right|\right)\right) \leqslant\left(b_{1} \wedge b_{2} M\right) M^{p-2} \sum_{k=1}^{n}\left|\operatorname{cov}\left(X_{k}, X_{k}\right)\right| \text {. }
$$

$\mathrm{P}$ r o of of $\mathrm{L}$ e $\mathrm{m} \mathrm{m}$ a 4 . For all positive integer $m$, and all positive real numbers $\alpha$ and $\beta$ that are conjugate (i.e., $1 / \alpha+1 / \beta=1$ ) there holds, thanks to Hölder's inequality

$$
\begin{aligned}
& \sum_{i=0}^{k-1} M^{m-2}(i+1)^{m-2}\left|\operatorname{cov}\left(X_{1}, X_{i+1}\right)\right| \leqslant\left(\sum_{i=0}^{k-1}\left|\operatorname{cov}\left(X_{1}, X_{i+1}\right)\right|\right)^{1 / \alpha} \\
& \quad \times\left(\sum_{i=0}^{k-1} M^{(m-2) \beta}(i+1)^{(m-2) \beta}\left|\operatorname{cov}\left(X_{1}, X_{i+1}\right)\right|\right)^{1 / \beta} .
\end{aligned}
$$

Taking the sum over $k \in\{1, \ldots, n\}$ in the last inequality and using again Hölder's inequality, we obtain

$$
M_{m, n} \leqslant s_{n}^{2 / \alpha}\left(\sum_{k=0}^{n} \sum_{i=0}^{k-1} M^{(m-2) \beta}(i+1)^{(m-2) \beta}\left|\operatorname{cov}\left(X_{1}, X_{i+1}\right)\right|\right)^{1 / \beta},
$$

hence, for $\alpha=(r-2) /(r-m)$ and $\beta=(r-2) /(m-2)$, we obtain $M_{m, n} \leqslant s_{n}^{2(r-m) /(r-2)} M_{r, n}^{(m-2) /(r-2)}$ and $\quad M_{r-m, n} \leqslant s_{n}^{2 m /(r-2)} M_{r, n}^{(r-m-2) /(r-2)}$.

The two last inequalities proves the first inequality in (18), the second one is trivial.

Now, we only prove (19) ((20) will hold with the same method). 
Clearly

$$
\begin{aligned}
& s_{n}^{r-m}\left(b_{1} \wedge b_{2} s_{n}\right)\left(\sum_{k=1}^{n} \sum_{i: M(i+1) \leqslant s_{n}}^{k-1} M^{m-2}(i+1)^{m-2}\left|\operatorname{cov}\left(X_{1}, X_{i+1}\right)\right|\right) \\
& \quad \leqslant s_{n}^{r-m}\left(b_{1} \wedge b_{2} s_{n}\right) s_{n}^{m-2}\left(\sum_{k=1}^{n} \sum_{i=0}^{k-1}\left|\operatorname{cov}\left(X_{1}, X_{i+1}\right)\right|\right) \leqslant s_{n}^{r}\left(b_{1} \wedge b_{2} s_{n}\right)
\end{aligned}
$$

and

$$
\sum_{k=1}^{n} \sum_{i: M(i+1) \geqslant s_{n}}^{k-1}\left(s_{n}^{r-m}\left(b_{1} \wedge b_{2} s_{n}\right) M^{m-2}(i+1)^{m-2}\left|\operatorname{cov}\left(X_{1}, X_{i+1}\right)\right|\right) \leqslant M_{r, n} .
$$

Collecting inequalities (23) and (24) we obtain (19).

Before going to the proof of the basic Lemma 3 , we will state an intermediate result needed for its proof. Define

$$
\mathbf{E}_{p-1, k}=\sum_{(p-1)}\left|\mathbf{E} X_{k} X_{k-i_{1}} \cdots X_{k-i_{p-1}}\right| .
$$

Lemma 5 ([10]). Let $\left(X_{n}\right)$ be a centered sequence of (AG) r.v.'s. Suppose that $\left(X_{n}\right)$ is uniformly bounded by $M$. Then, for any integer $p \geqslant 2$, there exists a positive constant $C_{p}$ for which

$$
\sum_{k=1}^{n} \mathbf{E}_{p-1, k} \leqslant C_{p}\left\{s_{n}^{p}+\sum_{k=1}^{n} \sum_{r=0}^{k-1} r^{p-2} M^{p-2}\left|\operatorname{cov}\left(X_{1}, X_{r+1}\right)\right|\right\}
$$

Lemma 5 was established by Doukhan and Louhichi [10], in order to give moment inequalities with integer order $p$ (cf. Theorem 4 in [10]).

$\mathrm{P}$ r o of of $\mathrm{L}$ e $\mathrm{mm}$ a 3 . We will prove, using an induction on $p \geqslant 2$, that each of the terms $\sum_{k=1}^{n} \mathbf{E}_{p-2, k}(\Delta f)$ and $\sum_{k=1}^{n} \mathbf{E}_{p-2, k}(f)$ are bounded by the RHS of (11).

For $p=2$, we refer to [15]. The calculations for the case $p=2$ are also deduced from the general case that we state just below.

Suppose now that (11) holds for the order $(p-1)$, we will prove it for $p$.

Our purpose is then to evaluate the following sums:

$$
\begin{aligned}
& \sum_{k=1}^{n} \sum_{(p-2)}\left|\mathbf{E} X_{k} X_{k-i_{1}} \cdots X_{k-i_{p-2}} f\left(S_{k-i_{p-2}-1}\right)\right|, \\
& \sum_{k=1}^{n} \sum_{(p-2)}\left|\mathbf{E} X_{k} X_{k-i_{1}} \cdots X_{k-i_{p-2}} \Delta_{p-2, k}(f)\right| .
\end{aligned}
$$

We argue as Doukhan and Portal [8]: let $0=: i_{0} \leqslant i_{1} \leqslant \cdots \leqslant i_{p-2} \leqslant k-1$ be a fixed sequence of increasing integers, let $m$ be the smallest integer for which $r_{m}:=i_{m+1}-i_{m}=\max _{1 \leqslant q \leqslant p-2}\left(i_{q}-i_{q-1}\right)$. Finally let $\sum_{(p-2)}^{(m)}$ denotes the sum over the subdivisions $i_{1} \leqslant \cdots \leqslant i_{p-2} \leqslant k-1$ for which the big hole $\max _{1 \leqslant q \leqslant p-2}\left(i_{q}-i_{q-1}\right)$ is reached at the index $m$. 
We also define $\sum_{(p-2)}^{(m), r_{m}}$ to be the sum over the subdivisions $i_{1} \leqslant \cdots \leqslant$ $i_{p-2}$ such that the big hole $i_{m+1}-i_{m}=\max _{1 \leqslant q \leqslant p-2}\left(i_{q}-i_{q-1}\right)$ equals to $r_{m}$.

Hence, if $B$ denotes a subset of $\mathbf{N}^{p-2}$ and $g$ is a positive function on $\mathbf{N}^{p-2}$, then

$$
\sum_{(p-2), B} g\left(i_{1}, \ldots, i_{p-2}\right) \leqslant \sum_{m=0}^{p-3} \sum_{r_{m}=0}^{k-1} \sum_{(p-2), B}^{(m), r_{m}} g\left(i_{1}, \ldots, i_{p-2}\right)
$$

we mean by $\sum_{(p-2), B}$ the sum over the subdivision $\left(i_{1}, \ldots, i_{p-2}\right)$ such that $\left(i_{1}, \ldots, i_{p-2}\right) \in B$ and $0=: i_{0} \leqslant i_{1} \leqslant \cdots \leqslant i_{p-2}$.

We will decompose the sum in (25) (respectively in (26)) into two sums, one over the subdivisions $0=: i_{0} \leqslant i_{1} \leqslant \cdots \leqslant i_{p-2}$ for which $i_{1}>A$ and the second over the subdivisions $0=: i_{0} \leqslant i_{1} \leqslant \cdots \leqslant i_{p-2}$ for which $i_{1} \leqslant A$, where the truncate term $A$ is defined by:

$$
A=\frac{b_{1}}{M b_{2}} \wedge(k-1) \text {. }
$$

(A) Bounds over the subdivisions $0=: i_{0} \leqslant i_{1} \leqslant \cdots \leqslant i_{p-2}$ such that $i_{1}>A$. We first need the following technical lemma that we check at the end of the proof of Lemma 3, as soon as all the evoked lemmas.

Lemma 6. Let $\left(X_{n}\right)$ be a centered sequence of (AG) r.v.'s. Suppose that $\left(X_{n}\right)$ is uniformly bounded by $M$. Then, for any integer $p \geqslant 2$, there exists a positive constant $C_{p}$ such that for any $f \in \mathscr{F}_{1}\left(b_{1}, b_{2}\right)$ :

$$
\begin{aligned}
\sum_{k=1}^{n} \sum_{m=0}^{p-3} \sum_{r_{m}=0}^{k-1} \sum_{(p-2)}^{(m), r_{m}} \mid \operatorname{cov}( & X_{k} \cdots X_{k-i_{m}}, X_{k-i_{m+1}} \cdots X_{k-i_{p-2}} \\
& \left.\times f\left(S_{k-i_{p-2}-1}\right)\right) \mid \mathbf{1}_{i_{1}>A} \\
\leqslant C_{p}\left\{s_{n}^{p}\left(b_{1} \wedge b_{2} s_{n}\right)+\right. & \left.M_{p, n}\left(b_{1}, b_{2}\right)\right\} .
\end{aligned}
$$

We obtain, using the trivial fact

$$
|\mathbf{E}(X Y)| \leqslant|\operatorname{cov}(X, Y)|+|\mathbf{E} X||\mathbf{E} Y|,
$$

inequalities (27) and (29):

$$
\begin{aligned}
& \sum_{k=1}^{n} \sum_{(p-2)}\left|\mathbf{E}\left(X_{k} \cdots X_{k-i_{p-2}} f\left(S_{k-i_{p-2}-1}\right)\right)\right| \mathbf{1}_{i_{1}>A} \\
& \quad \leqslant \sum_{k=1}^{n} \sum_{m=0}^{p-3} \sum_{(p-2)}^{(m)}\left|\mathbf{E} X_{k} X_{k-i_{1}} \cdots X_{k-i_{m}}\right|\left|\mathbf{E} X_{k-i_{m+1}} \cdots X_{k-i_{p-2}} f\left(S_{k-i_{p-2}-1}\right)\right| \\
& \quad+C_{p}\left\{s_{n}^{p}\left(b_{1} \wedge b_{2} s_{n}\right)+M_{p, n}\left(b_{1}, b_{2}\right)\right\} .
\end{aligned}
$$

We now evaluate the first term in the last inequality. For this, let $A_{p, n}$ (respectively $\left.A_{p, n}(f)\right)$ denote the sum $\sum_{k=1}^{n} \mathbf{E}_{p, k}$ (respectively $\sum_{k=1}^{n} \mathbf{E}_{p, k}(f)$ ). 
The inductive assumption and Lemma 5, together with Lemma 4, yield

$$
\begin{aligned}
& \sum_{k=1}^{n} \sum_{m=0}^{p-3} \sum_{(p-2)}^{(m)}\left|\mathbf{E} X_{k} X_{k-i_{1}} \cdots X_{k-i_{m}}\right|\left|\mathbf{E} X_{k-i_{m+1}} \cdots X_{k-i_{p-2}} f\left(S_{k-i_{p-2}-1}\right)\right| \\
& \leqslant \sum_{m=0}^{p-3} A_{m, n} A_{p-m-3, n}(f) \\
& \leqslant C_{p} \sum_{m=0}^{p-3}\left(s_{n}^{m+1}+M_{m+1, n}\right)\left(s_{n}^{p-m-1}\left(b_{1} \wedge b_{2} s_{n}\right)\right. \\
& \left.\quad+\sum_{m^{\prime}=2}^{p-m-3} M_{m^{\prime}, n} M_{p-m-1-m^{\prime}, n}\left(b_{1}, b_{2}\right)+M_{p-m-1, n}\left(b_{1}, b_{2}\right)\right) \\
& \leqslant C_{p}\left\{s_{n}^{p}\left(b_{1} \wedge b_{2} s_{n}\right)+\sum_{m=2}^{p-2} M_{m, n} M_{p-m, n}\left(b_{1}, b_{2}\right)+M_{p, n}\left(b_{1}, b_{2}\right)\right\} .
\end{aligned}
$$

Now, collecting inequalities (30) and (31), we obtain

$$
\begin{aligned}
& \sum_{k=1}^{n} \sum_{(p-2)} \mathbf{1}_{i_{1}>A}\left|\mathbf{E} X_{k} X_{k-i_{1}} \cdots X_{k-i_{p-2}} f\left(S_{k-i_{p-2}-1}\right)\right| \\
& \quad \leqslant C_{p}\left\{s_{n}^{p}\left(b_{1} \wedge b_{2} s_{n}\right)+\sum_{m=2}^{p-2} M_{m, n} M_{p-m, n}\left(b_{1}, b_{2}\right)+M_{p, n}\left(b_{1}, b_{2}\right)\right\} .
\end{aligned}
$$

In order to prove that

$$
\begin{aligned}
& \sum_{k=1}^{n} \sum_{(p-2)} \mathbf{1}_{i_{1}>A}\left|\mathbf{E} X_{k} X_{k-i_{1}} \cdots X_{k-i_{p-2}} \Delta_{p-2, k}(f)\right| \\
& \quad \leqslant C_{p}\left\{s_{n}^{p}\left(b_{1} \wedge b_{2} s_{n}\right)+\sum_{m=2}^{p-2} M_{m, n} M_{p-m, n}\left(b_{1}, b_{2}\right)+M_{p, n}\left(b_{1}, b_{2}\right)\right\},
\end{aligned}
$$

we argue as for the proof of (32), we just take $\Delta f$ instead of $f$, and we use the following inequality given by the lemma below, instead of (29).

Lemma 7. Let $\left(X_{n}\right)$ be a centered sequence of (AG) r.v.'s. Suppose that $\left(X_{n}\right)$ is uniformly bounded by $M$. Then, for any integer $p \geqslant 2$, there exists a positive constant $C_{p}$ such that for any $f \in \mathscr{F}_{1}\left(b_{1}, b_{2}\right)$ :

$$
\begin{aligned}
& \sum_{k=1}^{n} \sum_{m=0}^{p-3} \sum_{r_{m}=0}^{k-1} \sum_{(p-2)}^{(m), r_{m}}\left|\operatorname{cov}\left(X_{k} \cdots X_{k-i_{m}}, X_{k-i_{m+1}} \cdots X_{k-i_{p-2}} \Delta_{p-2, k}(f)\right)\right| \mathbf{1}_{i_{1}>A} \\
& \quad \leqslant C_{p} M_{p, n}\left(b_{1}, b_{2}\right) .
\end{aligned}
$$

(B) Bounds over the subdivisions $0=: i_{0} \leqslant i_{1} \leqslant \cdots \leqslant i_{p-2}$ such that $i_{1} \leqslant A$. Here we use analogous calculations as for $(\mathbf{A})$. Those calculations are applied to the function $f^{\prime}$ instead of $f$, whose expression appears thanks to Taylor's formula (cf. equality (21)). Let us explain more. 
First, we write

$$
f\left(S_{k-i_{p-2}-1}\right)=\sum_{i_{p-1}=i_{p-2}+1}^{i_{p-2}+r_{m}}\left[f\left(S_{k-i_{p-1}}\right)-f\left(S_{k-i_{p-1}-1}\right)\right]+f\left(S_{k-i_{p-2}-r_{m}-1}\right) .
$$

The last decomposition yields:

$$
\begin{aligned}
& \left|\mathbf{E}\left(X_{k} X_{k-i_{1}} \cdots X_{k-i_{p-2}} f\left(S_{k-i_{p-2}-1}\right)\right)\right| \\
& \quad \leqslant\left|\sum_{i_{p-1}=i_{p-2}+1}^{i_{p-2}+r_{m}} \mathbf{E}\left(X_{k} X_{k-i_{1}} \cdots X_{k-i_{p-2}}\left[f\left(S_{k-i_{p-1}}\right)-f\left(S_{k-i_{p-1}-1}\right)\right]\right)\right| \\
& \quad+\left|\mathbf{E}\left(X_{k} X_{k-i_{1}} \cdots X_{k-i_{p-2}} f\left(S_{k-i_{p-2}-r_{m}-1}\right)\right)\right| \\
& \quad=: J_{1}\left(i_{1}, \ldots, i_{p-2}\right)+J_{2}\left(i_{1}, \ldots, i_{p-2}\right) .
\end{aligned}
$$

Evaluation of $\sum_{(p-2)} J_{2}\left(i_{1}, \ldots, i_{p-2}\right) \mathbf{1}_{i_{1} \leqslant A}$. We deduce, since $\mathbf{E}(X Y)=$ $\operatorname{cov}(X, Y)+\mathbf{E}(X) \mathbf{E}(Y)$, that

$$
\begin{aligned}
\mathbf{E}( & \left.X_{k} X_{k-i_{1}} \cdots X_{k-i_{p-2}} f\left(S_{k-i_{p-2}-r_{m}-1}\right)\right) \\
= & \operatorname{cov}\left(X_{k} X_{k-i_{1}} \cdots X_{k-i_{p-2}}, f\left(S_{k-i_{p-2}-r_{m}-1}\right)\right) \\
& +\mathbf{E}\left(X_{k} X_{k-i_{1}} \cdots X_{k-i_{p-2}}\right) \mathbf{E}\left(f\left(S_{k-i_{p-2}-r_{m}-1}\right)\right) .
\end{aligned}
$$

The function $f$ belongs to the set $\mathscr{F}_{1}\left(b_{1}, b_{2}\right)$, hence using Taylor's formula (recall that $f(0)=f^{\prime}(0)=0$ ), we obtain $|f(x)| \leqslant b_{1}|x|,|f(x)| \leqslant b_{2} x^{2}$, this yields

$$
\left|\mathbf{E}\left(f\left(S_{k-i_{p-2}-r_{m}-1}\right)\right)\right| \leqslant s_{n}\left(b_{1} \wedge b_{2} s_{n}\right) .
$$

We deduce from the last bound, Lemmas 5 and 4 , that

$$
\begin{aligned}
& \sum_{k=1}^{n} \sum_{(p-2)}\left|\mathbf{E}\left(X_{k} X_{k-i_{1}} \cdots X_{k-i_{p-2}}\right) \mathbf{E}\left(f\left(S_{k-i_{p-2}-r_{m}-1}\right)\right)\right| \\
& \quad \leqslant\left(M_{p-1, n}+s_{n}^{p-1}\right) s_{n}\left(b_{1} \wedge b_{2} s_{n}\right) \leqslant M_{p, n}\left(b_{1}, b_{2}\right)+2 s_{n}^{p}\left(b_{1} \wedge b_{2} s_{n}\right) .
\end{aligned}
$$

In order to evaluate the first term of the RHS of (36), we use the following lemma.

Lemma 8. Let $\left(X_{n}\right)$ be a centered sequence of (AG) r.v.'s. Suppose that $\left(X_{n}\right)$ is uniformly bounded by $M$. Then, for any integer $p \geqslant 2$, there exists a positive constant $C_{p}$ such that for any $f \in \mathscr{F}_{1}\left(b_{1}, b_{2}\right)$ :

$$
\begin{gathered}
\sum_{k=1}^{n} \sum_{m=0}^{p-3} \sum_{r_{m}=0}^{k-1} \sum_{(p-1)}^{(m), r_{m}} \sup _{u \in[0,1]} \mid \operatorname{cov}\left(X_{k} \cdots X_{k-i_{m}}, X_{k-i_{m+1}} \cdots X_{k-i_{p-1}}\right. \\
\left.\times f^{\prime}\left(S_{k-i_{p-1}-1}+u X_{k-i_{p-1}}\right)\right) \mid \mathbf{1}_{i_{1} \leqslant A} \\
\leqslant C_{p}\left\{M_{p, n}\left(b_{1}, b_{2}\right)+s_{n}^{p}\left(b_{1} \wedge b_{2} s_{n}\right)\right\} .
\end{gathered}
$$


Now, the decomposition (21) yields:

$$
\begin{aligned}
& \sum_{(p-2)}^{(m), r_{m}}\left|\operatorname{cov}\left(X_{k} X_{k-i_{1}} \cdots X_{k-i_{p-2}}, f\left(S_{k-i_{p-2}-r_{m}-1}\right)\right)\right| \mathbf{1}_{i_{1} \leqslant A} \\
& \leqslant \sum_{(p-2)}^{(m), r_{m}} \sum_{i_{p-1}=i_{p-2}+r_{m}+1}^{k-1} \sup _{u \in[0,1]} \mid \operatorname{cov}\left(X_{k} \cdots X_{k-i_{p-2}}, X_{k-i_{p-1}}\right. \\
& \left.\times f^{\prime}\left(S_{k-i_{p-1}-1}+u X_{k-i_{p-1}}\right)\right) \mid \mathbf{1}_{i_{1} \leqslant A} .
\end{aligned}
$$

We take the sums over $m: 0 \leqslant m \leqslant p-3, r_{m}: 0 \leqslant r_{m} \leqslant k-1$ and over $k: 1 \leqslant k \leqslant n$ in the two last inequalities, and we use Lemma 8 to obtain:

$$
\begin{aligned}
& \sum_{k=1}^{n} \sum_{m=0}^{p-3} \sum_{r_{m}=0}^{k-1} \sum_{(p-2)}^{(m), r_{m}}\left|\operatorname{cov}\left(X_{k} X_{k-i_{1}} \cdots X_{k-i_{p-2}}, f\left(S_{k-i_{p-2}-r_{m}-1}\right)\right)\right| \mathbf{1}_{i_{1} \leqslant A} \\
& \quad \leqslant C_{p}\left\{M_{p, n}\left(b_{1}, b_{2}\right)+s_{n}^{p}\left(b_{1} \wedge b_{2} s_{n}\right)\right\}
\end{aligned}
$$

We deduce from (36), (38) and (39) that

$$
\begin{aligned}
& \sum_{k=1}^{n} \sum_{m=0}^{p-3} \sum_{r_{m}=0}^{k-1} \sum_{(p-2)}^{(m), r_{m}}\left|J_{2}\left(i_{1}, \ldots, i_{p-2}\right)\right| \mathbf{1}_{i_{1} \leqslant A} \\
& \quad \leqslant C_{p}\left\{M_{p, n}\left(b_{1}, b_{2}\right)+s_{n}^{p}\left(b_{1} \wedge b_{2} s_{n}\right)\right\} .
\end{aligned}
$$

Evaluation of $\sum_{(p-2)} J_{1}\left(i_{1}, \ldots, i_{p-2}\right) \mathbf{1}_{i_{1} \leqslant A}$.

The two sums $\sum_{(p-2)}^{(m), r_{m}} \sum_{i_{p-1}=i_{p-2}+1}^{i_{p-2}+r_{m}}$ are taken over the subdivisions $0 \leqslant$ $i_{1} \leqslant \cdots \leqslant i_{p-1} \leqslant k-1$ such that $r_{m}=\max _{1 \leqslant q \leqslant p-2}\left(i_{q}-i_{q-1}\right)$ and that $i_{p-1}-i_{p-2} \leqslant r_{m}$, hence $r_{m}$ is also the big hole of the subdivision $0 \leqslant i_{1} \leqslant$ $\cdots \leqslant i_{p-1} \leqslant k-1$, that is, $r_{m}=\max _{1 \leqslant q \leqslant p-1}\left(i_{q}-i_{q-1}\right)$.

We then deduce

$$
\begin{gathered}
\sum_{(p-2)}^{(m), r_{m}} \mathbf{1}_{i_{1} \leqslant A}\left|\mathbf{E}\left(X_{k} X_{k-i_{1}} \cdots X_{k-i_{p-2}}\left[f\left(S_{k-i_{p-2}-1}\right)-f\left(S_{k-i_{p-2}-r_{m}-1}\right)\right]\right)\right| \\
\leqslant \sum_{(p-1)}^{(m), r_{m}} \mathbf{1}_{i_{1} \leqslant A} \sup _{u \in[0,1]} \mid \operatorname{cov}\left(X_{k} \cdots X_{k-i_{m}}, X_{k-i_{m+1}} \cdots X_{k-i_{p-1}}\right. \\
\times f^{\prime}\left(S_{k-i_{p-1}-1}+u X_{k-i_{p-1}}\right) \mid \\
+\sum_{(p-1)}^{(m), r_{m}} \mid \mathbf{E}\left(X_{k} \cdots X_{k-i_{m}}\right) \mathbf{E}\left(X_{k-i_{m+1}} \cdots X_{k-i_{p-2}}\right. \\
\left.\times\left[f\left(S_{k-i_{p-1}}\right)-f\left(S_{k-i_{p-1}-1}\right)\right]\right) \mid \mathbf{1}_{i_{1} \leqslant A} .
\end{gathered}
$$

In order to give a bound for the sums over $k, m$ and $r_{m}$ of the RHS of (41), we argue as for the proof of (32): we use the inductive assumption to bound the second term of the RHS of (41) (as in (31)) and we use Lemma 8 instead 
of Lemma 6 in order to evaluate the first term in the RHS of (41). We thus obtain:

$$
\begin{aligned}
& \sum_{k=1}^{n} \sum_{m=0}^{p-3} \sum_{r_{m}=0}^{k-1} \sum_{(p-2)}^{(m), r_{m}}\left|J_{1}\left(i_{1}, \ldots, i_{p-2}\right)\right| \mathbf{1}_{i_{1} \leqslant A} \\
& \quad \leqslant C_{p}\left\{\sum_{m=2}^{p-2} M_{m, n} M_{p-m, n}\left(b_{1}, b_{2}\right)+M_{p, n}\left(b_{1}, b_{2}\right)+s_{n}^{p}\left(b_{1} \wedge b_{2} s_{n}\right)\right\} .
\end{aligned}
$$

Inequalities (35), (40), (42) prove that

$$
\begin{aligned}
& \sum_{k=1}^{n} \sum_{(p-2)} \mathbf{1}_{i_{1} \leqslant A}\left|\mathbf{E} X_{k} X_{k-i_{1}} \cdots X_{k-i_{p-2}} f\left(S_{k-i_{p-2}-1}\right)\right| \\
& \quad \leqslant C_{p}\left\{s_{n}^{p}\left(b_{1} \wedge b_{2} s_{n}\right)+\sum_{m=2}^{p-2} M_{m, n} M_{p-m, n}\left(b_{1}, b_{2}\right)+M_{p, n}\left(b_{1}, b_{2}\right)\right\} .
\end{aligned}
$$

The last inequality together with (32) proves that the quantity in (25) is bounded by the RHS of (11).

Let us now give a bound for (26).

Using again the fact $|\mathbf{E}(X Y)| \leqslant|\operatorname{cov}(X, Y)|+|\mathbf{E} X||\mathbf{E} Y|$, the second equality of (21), the inductive assumption and Lemma 8 , we obtain:

$$
\begin{aligned}
& \sum_{k=1}^{n} \sum_{(p-2)}\left|\mathbf{E} X_{k} X_{k-i_{1}} \cdots X_{k-i_{p-2}} \Delta_{p-2, k}(f)\right| \mathbf{1}_{i_{1} \leqslant A} \\
& \quad \leqslant C_{p}\left\{s_{n}^{p}\left(b_{1} \wedge b_{2} s_{n}\right)+\sum_{m=2}^{p-2} M_{m, n} M_{p-m, n}\left(b_{1}, b_{2}\right)+M_{p, n}\left(b_{1}, b_{2}\right)\right\} .
\end{aligned}
$$

This last bound together with (33) proves that the quantity in (26) is bounded by the RHS of (11), for all integer $p \geqslant 2$. The proof of Lemma 3 is thus finished.

We now prove Lemmas 6, 7, and 8 .

P r o of of $\mathrm{L}$ e $\mathrm{m} \mathrm{m}$ a 6 . The $(\mathrm{AG})$ property yields

$$
\begin{aligned}
& \left|\operatorname{cov}\left(X_{k} \cdots X_{k-i_{m}}, X_{k-i_{m+1}} \cdots X_{k-i_{p-2}}\left[f\left(S_{k-i_{p-2}-1}\right)-f\left(S_{k-i_{p-2}-r_{m}-1}\right)\right]\right)\right| \\
& \leqslant C_{p} M^{p-2} b_{1} r_{m} \sum_{l=r_{m}}^{k-1}\left|\operatorname{cov}\left(X_{1}, X_{l}\right)\right| .
\end{aligned}
$$

Now, the definition of $r_{m}$, i.e., $r_{m}=i_{m+1}-i_{m}=\max _{1 \leqslant q \leqslant p-2}\left(i_{q}-i_{q-1}\right)$, implies that $r_{m} \geqslant i_{1}-i_{0}=i_{1}$ and $j r_{m} \geqslant i_{j}$ for all integer $j$ smaller than $p-2$. Thus

$$
\begin{aligned}
I_{r_{m}} & :=\sum_{(p-2)}^{(m), r_{m}} M^{p-2} b_{1} r_{m} \sum_{l=r_{m}}^{k-1}\left|\operatorname{cov}\left(X_{1}, X_{l}\right)\right| \mathbf{1}_{i_{1}>A} \\
& \leqslant M^{p-2} b_{1} r_{m}^{p-2} \sum_{l=r_{m}}^{k-1}\left|\operatorname{cov}\left(X_{1}, X_{l}\right)\right| \mathbf{1}_{r_{m}>A}
\end{aligned}
$$


We obtain, taking the sum over $r_{m}$ in the last inequality, using (28) and the trivial fact $x \mathbf{1}_{y \geqslant x} \leqslant x \wedge y$, for positive real numbers $x, y$,

$$
\sum_{r_{m}=0}^{k-1} I_{r_{m}} \leqslant \sum_{l=0}^{k-1} l^{p-2} M^{p-2}\left(b_{1} \wedge b_{2} M(l+1)\right)\left|\operatorname{cov}\left(X_{1+l}, X_{1}\right)\right| .
$$

Finally, we take the sums over $m \in\{0, \ldots, p-3\}, k \in\{1, \ldots, n\}$ in the last inequality to get

$$
\begin{gathered}
\sum_{k=1}^{n} \sum_{m=0}^{p-3} \sum_{r_{m}=0}^{k-1} \sum_{(p-2)}^{(m), r_{m}} \mid \operatorname{cov}\left(X_{k} \cdots X_{k-i_{m}}, X_{k-i_{m+1}} \cdots X_{k-i_{p-2}}\right. \\
\left.\times\left[f\left(S_{k-i_{p-2}-1}\right)-f\left(S_{k-i_{p-2}-r_{m}-1}\right)\right]\right) \mid \\
\leqslant \sum_{k=1}^{n} \sum_{l=0}^{k-1} l^{p-2} M^{p-2}\left(b_{1} \wedge b_{2} M(l+1)\right)\left|\operatorname{cov}\left(X_{1+l}, X_{1}\right)\right| .
\end{gathered}
$$

We now use the trivial fact

$$
\begin{aligned}
\operatorname{cov}(X, Y Z)= & \operatorname{cov}(X Y, Z)+\mathbf{E}(X Y) \mathbf{E}(Z)-\mathbf{E}(X) \operatorname{cov}(Y, Z) \\
& -\mathbf{E}(X) \mathbf{E}(Y) \mathbf{E}(Z),
\end{aligned}
$$

to get

$$
\begin{aligned}
\mid \operatorname{cov} & \left(X_{k} \cdots X_{k-i_{m}}, X_{k-i_{m+1}} \cdots X_{k-i_{p-2}} f\left(S_{k-i_{p-2}-r_{m}-1}\right)\right) \mid \\
\leqslant & \left|\operatorname{cov}\left(X_{k} \cdots X_{k-i_{p-2}}, f\left(S_{k-i_{p-2}-r_{m}-1}\right)\right)\right| \\
& +\left|\mathbf{E}\left(X_{k} \cdots X_{k-i_{p-2}}\right) \mathbf{E}\left(f\left(S_{k-i_{p-2}-r_{m}-1}\right)\right)\right| \\
& +\left|\mathbf{E}\left(X_{k} \cdots X_{k-i_{m}}\right) \operatorname{cov}\left(X_{k-i_{m+1}} \cdots X_{k-i_{p-2}}, f\left(S_{k-i_{p-2}-r_{m}-1}\right)\right)\right| \\
& +\left|\mathbf{E}\left(X_{k} \cdots X_{k-i_{m}}\right) \mathbf{E}\left(X_{k-i_{m+1}} \cdots X_{k-i_{p-2}}\right) \mathbf{E}\left(f\left(S_{k-i_{p-2}-r_{m}-1}\right)\right)\right| \\
= & : I_{1}\left(i_{1}, \ldots, i_{p-2}\right)+I_{2}\left(i_{1}, \ldots, i_{p-2}\right)+I_{3}\left(i_{1}, \ldots, i_{p-2}\right)+I_{4}\left(i_{1}, \ldots, i_{p-2}\right) .
\end{aligned}
$$

Lemmas 5, 4 and inequality (37) yield

$$
\begin{aligned}
& \sum_{k=1}^{n} \sum_{(p-2)} I_{2}\left(i_{1}, \ldots, i_{p-2}\right)+\sum_{k=1}^{n} \sum_{(p-2)} I_{4}\left(i_{1}, \ldots, i_{p-2}\right) \\
& \leqslant C_{p} \sum_{l=0}^{k-1} l^{p-2} M^{p-2}\left(b_{1} \wedge b_{2} M(l+1)\right)\left|\operatorname{cov}\left(X_{1+l}, X_{1}\right)\right| \\
& \quad+C_{p} s_{n}^{p}\left(b_{1} \wedge b_{2} s_{n}\right) .
\end{aligned}
$$

The (AG) property yields

$$
\left|\operatorname{cov}\left(X_{k} \cdots X_{k-i_{p-2}}, f\left(S_{k-i_{p-2}-r_{m}-1}\right)\right)\right| \leqslant C_{p} M^{p-2} b_{1} \sum_{l=r_{m}}^{k-1}\left|\operatorname{cov}\left(X_{1}, X_{l}\right)\right| \text {. }
$$

Hence

$$
\sum_{k=1}^{n} \sum_{m=2}^{p-3} \sum_{r_{m}=0}^{k-1} \sum_{(p-2)}^{(m), r_{m}} \mathbf{1}_{i_{1}>A} I_{1}\left(i_{1}, \ldots, i_{p-2}\right) \leqslant C_{p} M_{p, n}\left(b_{1}, b_{2}\right)
$$


Using the (AG) property (as for (45)), Lemmas 5 and 4, we obtain

$$
\sum_{k=1}^{n} \sum_{(p-2)} \mathbf{1}_{i_{1}>A} I_{3}\left(i_{1}, \ldots, i_{p-2}\right) \leqslant C_{p}\left\{M_{p, n}\left(b_{1}, b_{2}\right)+s_{n}^{p}\left(b_{1} \wedge b_{2} s_{n}\right)\right\} .
$$

Finally the proof of Lemma 6 is complete by adding inequalities (43), (44), (46) and (47).

Pro of of $\mathrm{L}$ e m m 7 . The (AG) property and the fact that $r_{m} \geqslant i_{1}$ yield

$$
\begin{aligned}
& \left|\operatorname{cov}\left(X_{k} \cdots X_{k-i_{m}}, X_{k-i_{m+1}} \cdots X_{k-i_{p-2}} \Delta_{p-2, k}(f)\right)\right| \mathbf{1}_{i_{1}>A} \\
& \quad \leqslant C_{p} M^{p-2} b_{1} \sum_{l=r_{m}}^{k-1}\left|\operatorname{cov}\left(X_{1}, X_{l}\right)\right| \mathbf{1}_{l>A} .
\end{aligned}
$$

Hence

$$
\begin{gathered}
\sum_{k=1}^{n} \sum_{m=0}^{p-3} \sum_{r_{m}=0}^{k-1} \sum_{(p-2)}^{(m), r_{m}}\left|\operatorname{cov}\left(X_{k} \cdots X_{k-i_{m}}, X_{k-i_{m+1}} \cdots X_{k-i_{p-2}} \Delta_{p-2, k}(f)\right)\right| \mathbf{1}_{i_{1}>A} \\
\leqslant C_{p} \sum_{k=1}^{n} \sum_{r_{m}=0}^{k-1} M^{p-2} b_{1} \sum_{l=r_{m}}^{k-1}\left|\operatorname{cov}\left(X_{1}, X_{l}\right)\right| \mathbf{1}_{l>A} \leqslant C_{p} M_{p, n}\left(b_{1}, b_{2}\right) \\
\text { P r o of of L e m m a } 8 \text {. We write } \\
f^{\prime}\left(S_{k-i_{p-1}-1}+u X_{k-i_{p-1}}\right)= \\
\left.+f^{\prime}\left(S_{k-i_{p-1}-1}+u X_{k-i_{p-1}}\right)-f^{\prime}\left(S_{k-i_{p-1}-1}\right)\right] \\
+f^{\prime}\left(S_{k-i_{p-1}-1}\right)
\end{gathered}
$$

so the covariance quantity of Lemma 8 is decomposed into two terms:

$$
\left|\operatorname{cov}\left(X_{k} \cdots X_{k-i_{m}}, X_{k-i_{m+1}} \cdots X_{k-i_{p-1}} f^{\prime}\left(S_{k-i_{p-1}-1}\right)\right)\right| \mathbf{1}_{i_{1} \leqslant A}
$$

and

$$
\begin{aligned}
\mid \operatorname{cov}( & X_{k} \cdots X_{k-i_{m}}, X_{k-i_{m+1}} \cdots X_{k-i_{p-1}} \\
& \left.\times\left[f^{\prime}\left(S_{k-i_{p-1}-1}+u X_{k-i_{p-1}}\right)-f^{\prime}\left(S_{k-i_{p-1}-1}\right)\right]\right) \mid \mathbf{1}_{i_{1} \leqslant A}
\end{aligned}
$$

which are evaluated as the covariance quantities of Lemmas 6 and 7.

Acknowledgments. We are very grateful to the referee for his careful reading of this paper.

\section{REFERENCES}

1. Bickel P. J, Bühlmann P. A new mixing notion and functional central limit theorems for a sieve bootstrap in time series. - Bernoulli, 1999, v. 5, № 3, p. 413-446.

2. Birkel T. Moment bounds for associated sequences. - Ann. Probab., 1988, v. 16, № 3, p. 1184-1193.

3. Birkel T. On the convergence rate in the central limit theorem for associated processes. - Ann. Probab., 1988, v. 16, № 4, p. 1685-1698. 
4. Bretagnolle J., Huber C. Estimation des densités: risque minimax. — Z. Wahrscheinlichkeitstheor. verw. Geb., 1979, v. 47, p. 119-137.

5. Бахтин Ю.Ю., Булинский А.В. Моментные неравенства для сумм зависимых мультииндексированных случайных величин. - Фунд. прикл. матем., 1997, т. 3, № 4, с. 1101-1108.

6. Булинский $A$. B. Неравенства для моментов сумм ассоциированных мультииндексированных величин. - Теория вероятн. и ее примен., 1993, т. 38, в. 2, с. 417-425.

7. Bulinskii A. V. On the convergence rates in the CLT for positively and negatively dependent random fields. - Probability Theory and Mathematical Statistics. Ed. by I. A. Ibragimov and A. Yu. Zaitsev. Singapore: Gordon and Breach, 1996, p. 3-14.

8. Doukhan P., Portal F. Moments de variables aléatoires mélangeantes. - C. R. Acad. Sci. Paris, Sér. I, 1983, v. 297, p. 129-132.

9. Doukhan P. Mixing: Properties and Examples. Berlin-Heidelberg: Springer-Verlag, 1994, $142 \mathrm{p}$.

10. Doukhan P., Louhichi S. A new weak dependence condition and applications to moment inequalities. - Stochastic Process. Appl., 1999, v. 84, № 2, p. 313-342.

11. Esary J., Proschan F., Walkup D. Association of random variables with applications. - Ann. Math. Statist., 1967, v. 38, p. 1466-1476.

12. Fortuin C., Kasteleyn P., Ginibre J. Correlation inequalities on some partially ordered sets. - Comm. Math. Phys., 1971, v. 22, p. 89-103.

13. Ибрагимов И.А., Линник Ю.В. Независимые и стационарно связанные величины. М.: Наука, 1965, 524 с.

14. Joag-Dev $K$. Independence via uncorrelatedness under certain dependence structures. - Ann. Probab., 1983, v. 11, № 4, p. 1037-1041.

15. Louhichi $S$. Rates of convergence in the CLT for some weakly dependent random variables. - Теория вероятн. и ее примен., 2001, т. 46, в. 2, с. 345-364.

16. Matula $P$. Probability and moment bounds for sums of negatively associated random variables. - Teor. Imovirnost. ta Matem. Statyst., 1996, v. 55, p. 130-135.

17. Пешкир $Г$., Ширяев А.Н. Неравенства Хинчина и мартингальное расширение сферы их действия. - Успехи матем. наук, 1995, т. 50, № 5, с. 3-62.

18. Petrov V.V. Limit Theorems of Probability Theory: Sequences of Independent Random Variables. Oxford: Clarendon Press, 1995, 292 p.

19. Rio E. Inégalités de moments pour les suites stationnaires et fortement mélangeantes. - C. R. Acad. Sci. Paris, Sér. I, 1994, v. 318, № 4, p. 355-360.

20. Rio E. About the Lindeberg method for strongly mixing sequences. - ESAIM Probab. Statist., 1995, v. 1, p. 35-61.

21. Rosenthal H.P. On the subspaces of $L^{p}(p>2)$ spanned by sequences of independent random variables. - Israel J. Math., 1970, v. 8, p. 273-303.

22. Shao Q. M. Maximal inequalities for partial sums of $\rho$-mixing sequences. - Ann. Probab., 1995, v. 23, № 2, p. 948-965.

23. Shao Q. M., Yu H. Weak convergence for weighted empirical processes of dependent sequences. - Ann. Probab., 1996, v. 24, № 4, p. 2098-2127.

24. Shao Q.M., Su C. The law of the iterated logarithm for negatively associated random variables. - Stochastic Process. Appl., 1999, v. 83, № 1, p. 139-148.

25. Shao Q. M. A comparison theorem on moment inequalities between negatively associated and independent random variables. - J. Theoret. Probab., 2000, v. 13, № 2, p. 343-356.

26. Stout W. F. Almost Sure Convergence. New York: Academic Press, 1974, 381 p.

27. Вронский М. А. Скорость сходимости в УЗБЧ для ассоциированных последовательностей и полей. - Теория вероятн. и ее примен., 1998, т. 43, в. 3, с. 449-462.

Поступила в редакцию 5.IV.2000 